\title{
Revision on Material Strength of Steel Fiber-Reinforced Concrete
}

\author{
Kyoung-Wan Karl, ${ }^{1)}$ Deuck Hang Lee, ${ }^{2)}$ Jin-Ha Hwang, ${ }^{2)}$ \\ Kang Su Kim, ${ }^{2) * *}$ and II-Sup Choi ${ }^{1)}$
}

(Received March 17 2011, Revised September 15, 2011, Accepted September 15, 2011)

\begin{abstract}
Many studies have been performed on steel fiber-reinforced normal/high-strength concrete (SFRC, SFRHC) for years, which is to improve some of the weak material properties of concrete. Most of equations for material strengths of SFRHC, however, were proposed based on relatively limited test results. In this research, therefore, the material test results of SFR(H)C were extensively collected from literature, and material tests have conducted on $\mathrm{SFR}(\mathrm{H}) \mathrm{C}$; compressive strength tests, splitting tensile tests, and modulus of rupture tests. Based on the extensive test data obtained from previous studies and this research, a database of SFR $(H) C$ material strengths has been established, and improved equations for material strengths of SFR(H)C were also proposed. Test results showed that both the splitting tensile strength and the modulus of rupture of SFR(H)C increased as the volume fraction of steel fiber increased, while the effect of the steel fiber volume fraction on the compressive strength of SFR(H)C were not clearly observed. The proposed equations for the splitting tensile strength and the modulus of rupture of SFR(H)C showed better results than the previous equations examined in this study in terms of not only accuracy but also safety/reliability.
\end{abstract}

Keywords: fiber, SFRC, compressive strength, splitting tensile strength, modulus of rupture.

\section{Introduction}

Due to the continuous increase in demand for high-strength and high-performance construction materials, many ongoing researches are being conducted to improve the structural performance of concrete material that has been widely used in buildings, bridges, and other structures. ${ }^{1-10}$ Many studies are especially focusing on steel fiber-reinforced concrete (SFRC), because it has excellent characteristics as a structural material such as higher tensile strength and shear strength than conventional concrete, and also excellent crack control performance. Its supply and application are comparatively easy as well. ${ }^{1-10}$

In order to actually apply SFRC to the practical field, however, its material strength should be properly estimated with the adequate margin of safety and reliability. Many studies have been conducted to clarify the characteristics of SFRC material, but questions still remain on the reliability and safety of material strengths of SFRC. ${ }^{11,12}$ There is also a lack of experimental studies on high-strength concrete mixed with steel fibers, which has recently been used in the construction field. Therefore, this study provides experimental results on compressive strength, tensile strength, and modulus of rupture of SFRC mixtures containing steel fiber-reinforced high strength concrete (SFRHC). This study also proposes the evaluation equations for the material strengths of

\footnotetext{
${ }^{1}$ Yun-Woo Structural Engineering Co. Ltd., Seoul 135-010, Korea.

${ }^{2)}$ University of Seoul, Department of Architectural Engineering, Seoul 130-743, Korea. *Corresponding Author; E-mail: kangkim@uos.ac.kr

Copyright (c) 2011, Korea Concrete Institute. All rights reserved, including the making of copies without the written permission of the copyright proprietors.
}

SFRC and SFRHC that consider adequate margin of safety and reliability, which are evaluated by the experimental test results obtained from this study together with those from literatures.

\section{Review of previous researches}

Narayanan and Darwish ${ }^{13}$ conducted splitting tensile strength tests on SFRC with variables of concrete compressive strength $\left(f_{c k}\right)$ and fiber shape factor $\left(\alpha_{f}\right)$. Based on their experimental results and those of existing studies, the splitting tensile strength $\left(f_{\text {spf }}\right)$ of SFRC was proposed as:

$$
f_{s p f}=\frac{f_{c u f}}{20-\sqrt{F_{1}}}+0.7+\sqrt{F_{1}}
$$

where, $f_{\text {cuf }}$ is the cubic compressive strength of the SFRC, $F_{1}$ is the fiber factor which is defined as $V_{f} L_{f} a_{f} / D_{f}$. Here, $V_{f}$ is the volume fraction of steel fibers, $L_{f}$ is the length of the steel fiber, and $D_{f}$ is the diameter of the steel fiber.

Wafa and Ashour ${ }^{14}$ conducted many material tests with volume fraction of steel fibers $\left(V_{f}\right)$ as the key variable, and the compressive strength $\left(f_{c k f}\right)$, splitting tensile strength $\left(f_{\text {sp } f}\right)$, and modulus of rupture $\left(f_{r f}\right)$ of SFRC were proposed, respectively, as:

$$
\begin{aligned}
& f_{c k f}=f_{c k}+3.53 V_{f} \\
& f_{s p f}=0.58 \sqrt{f_{c k}}+3.02 V_{f} \\
& f_{r t}=0.99 \sqrt{f_{c k}}+3.83 V_{f}
\end{aligned}
$$

where, $f_{c k}$ is the compressive strength of concrete. 
Eren and Celik ${ }^{15}$ made a total of thirty mixtures with various ranges of volume fraction of steel fibers $\left(V_{f}\right)$, fiber factor $\left(F_{1}\right)$ and silica fume addition.Based on test results, they proposed the splitting tensile strength $\left(f_{s p f}\right)$ of $\mathrm{SFR}(\mathrm{H}) \mathrm{C}$ as follows:

$$
\begin{aligned}
& f_{s p f}=A\left(V_{f}\right)+B \\
& f_{s p f}=C\left(\sqrt{f_{c k}}\right)+D
\end{aligned}
$$

Equation (3-1) and equation (3-2) considers the effect of the volume fraction of steel fibers $\left(V_{f}\right)$ and the compressive strength of the concrete $\left(f_{c k}\right)$, respectively. A, B, C, and D are coefficients that were determined based on regression analysis, and were proposed by Eren and Celik with different values according to the characteristics of SFRC. $^{15}$

Song and Hwang ${ }^{16}$ also reported test results on SFRHCs having various volume fraction of steel fibers $\left(V_{f}\right)$, and proposed compressive strength $\left(f_{c k f}\right)$, splitting tensile strength $\left(f_{s p f}\right)$ and flexural modulus of rupture $\left(f_{r f}\right)$ as follows, respectively:

$$
\begin{aligned}
& f_{c k f}=f_{c k}+15.12 V_{f}+4.71 V_{f}^{2} \\
& f_{s p f}=0.63 \sqrt{f_{c k}}+3.01 V_{f}-0.02 V_{f}^{2} \\
& f_{r f}=0.69 \sqrt{f_{c k}}+3.43 V_{f}+0.32 V_{f}^{2}
\end{aligned}
$$

Thomas and Ramaswamy ${ }^{17}$ conducted a large number of material tests on $\mathrm{SFR}(\mathrm{H}) \mathrm{Cs}$, and proposed compressive strength $\left(f_{c k f}\right)$, splitting tensile strength $\left(f_{\text {spf }}\right)$ and flexural modulus of rupture $\left(f_{r f}\right)$ of $\mathrm{SFR}(\mathrm{H}) \mathrm{C}$, respectively, as follows:

$$
\begin{aligned}
& f_{c k f}=0.83 f_{c u}+0.046 f_{c u} F_{2}+1.02 F_{2} \\
& f_{s p f}=0.63 \sqrt{f_{c u}}+0.288 \sqrt{f_{c u}} F_{2}+0.052 F_{2} \\
& f_{r f}=0.97 \sqrt{f_{c u}}+0.295 \sqrt{f_{c u}} F_{2}+1.117 F_{2}
\end{aligned}
$$

where, $f_{c u}$ is the cubic compressive strength of conventional concrete, and $F_{2}$ is defined as, $F_{2}=V_{f} L_{f} / D_{f}$.

$\mathrm{Oh}^{5}$ performed parametric studies on the modulus of rupture of SFRHC $\left(f_{r f}\right)$, based on his test results, and proposed the modulus of rupture as follows:

$$
f_{r f}=0.63 \sqrt{f_{c k}}+0.75 F_{1} \sqrt{f_{c k}}
$$

As described above, many experimental studies have been conducted on the material characteristics of SFRC and SFRHC, and different equations for the material strengths were proposed. Most of the existing proposed equations for material strengths, however, are based on quite limited experimental results, and those need to be verified with comparisons of a larger number of material test results available by now. In addition, there has hardly been any consideration on the margin of safety of material strengths based on reliability of the characteristics of SFR(H)C. Therefore, additional material experiments on $\mathrm{SFR}(\mathrm{H}) \mathrm{C}$ were conducted in this study, and the experiment results from this study and those collected from literatures were used for a reliability analysis. Based on the analysis results and calibrations, material strength equations for $\operatorname{SFR}(\mathrm{H}) \mathrm{C}$ were proposed with a proper margin of safety.

\section{Experimental programs}

A total of sixteen SFR $(\mathrm{H})$ Cs were mixed with concrete compressive strength $\left(f_{c k}\right)$ and volume fraction of steel fibers $\left(V_{f}\right)$ as primary variables to investigate the material strength of SFRC. For each mix, three $\phi 100 \mathrm{~mm} \times 200 \mathrm{~mm}$ cylinders for compressive strength test, three $\phi 150 \mathrm{~mm} \times 300 \mathrm{~mm}$ splitting tensile strength test specimens, and a $150 \mathrm{~mm} \times 150 \mathrm{~mm} \times 530 \mathrm{~mm}$ modulus of rupture test prism were cast and tested.

Table 1 shows the concrete mixtures used in this study. Mixture 1 and Mixture 2 were designed to have target compressive strengths of $50 \mathrm{MPa}$ and $70 \mathrm{MPa}$, respectively. Ordinary Portland cement, graded crushed gravel, and river sand were used in this mixture, where a poly-carbonic acid type of $\mathrm{AE}$ water reducing agent was added to enhance workability. Table 2 shows the detail properties of steel fiber used in this study. The steel fiber was a hooked type, $30 \mathrm{~mm}$ in length $\left(L_{f}\right), 0.5 \mathrm{~mm}$ in diameter $\left(D_{f}\right)$, and had a tensile strength of 1,200 MPa.

As shown in Table 3, the volume fraction of steel fibers of test specimens were $0.0 \%, 0.5 \%, 1.0 \%, 1.5 \%$ and $2.0 \%$ and concrete compressive strengths were $50 \mathrm{MPa}$ and $70 \mathrm{MPa}$. Many of the specimens of groups A and B had the same variables, but they were divided into two groups because they were cast from different batches. $\mathrm{A} 1$ and $\mathrm{A} 5$, and $\mathrm{B} 1$ and $\mathrm{B} 5$ from the two groups were control specimens with $0 \%$ volume fraction of steel fibers $\left(V_{f}\right)$, that is, normal concrete.

\subsection{Test results of compressive strength}

Experimental results of compressive strength of SFRC $\left(f_{c k f}\right)$ conducted in this study are shown in Table 4 and Figure 1 . The values of $f_{c k f} / f_{c k}$ in Table 4 show the relative increase(or decrease) of test specimens compared to A1, A5, B1 and B5, which are control specimens with $0 \%$ volume fraction of steel fibers $\left(V_{f}\right)$ for each of $\mathrm{SFR}(\mathrm{H}) \mathrm{C}$ series. It is also noted that the compressive strength of SFRC shown in Table 4 is the average

Table 1 Concrete mix proportion.

\begin{tabular}{c|c|c|c|c|c|c|c|c|}
\hline \multirow{2}{*}{ No. } & \multirow{2}{*}{ W/C (\%) } & \multirow{2}{*}{$\mathrm{S} / \mathrm{a}(\%)$} & \multicolumn{5}{|c|}{ Unit weight $\left(\mathrm{kgf} / \mathrm{m}^{3}\right)$} & \multirow{2}{*}{$\mathrm{AE}(\%)$} \\
\cline { 4 - 9 } & & & $\mathrm{W}$ & $\mathrm{C}$ & $\mathrm{S}$ & $\mathrm{G}$ & $\mathrm{Si}$ & - \\
\hline \hline 1 & 33.2 & 40.6 & 194 & 584 & 635 & 945 & 55 & 1.5 \\
\hline 2 & 24.0 & 40.2 & 145 & 600 & 673 & 1068 & 55 \\
\hline
\end{tabular}

$\mathrm{W} / \mathrm{C}$ water to cement ratio, $\mathrm{S} / \mathrm{a}$ : fine aggregate ratio, $\mathrm{W}:$ water, $\mathrm{C}:$ cement, $\mathrm{S}:$ fine aggregate, $\mathrm{G}:$ coarse aggregate, $\mathrm{Si}: \mathrm{silica}$ fume, $\mathrm{AE}: \mathrm{AE}$ water reducing agent 
Table 2 Properties of steel fibers.

\begin{tabular}{c|c|c|c|c}
\hline Shape & $\begin{array}{c}\text { Length } \\
\left(L_{f}, \mathrm{~mm}\right)\end{array}$ & $\begin{array}{c}\text { Diameter } \\
\left(D_{f}, \mathrm{~mm}\right)\end{array}$ & $L_{f} / D_{f}$ & $\begin{array}{c}\text { Tensile strength } \\
\left(f_{\text {sfu }}, \mathrm{MPa}\right)\end{array}$ \\
\hline \hline Hooked & 30 & 0.5 & 60 & 1,200 \\
\hline
\end{tabular}

Table 3 Test variables of specimens.

\begin{tabular}{c|c|c|c|c|c}
\hline Name & $f_{c k}\left(f_{c k f}\right)$ & $V_{f}(\%)$ & Name & $f_{c k}\left(f_{c k f}\right)$ & $V_{f}$ \\
\hline \hline A1 & 50 & 0.0 & B1 & 50 & 0.0 \\
\hline A2 & 50 & 0.5 & B2 & 50 & 0.5 \\
\hline A3 & 50 & 1.0 & B3 & 50 & 1.0 \\
\hline A4 & 50 & 1.5 & B4 & 50 & 1.5 \\
\hline A5 & 70 & 0.0 & B5 & 70 & 0.0 \\
\hline A6 & 70 & 0.5 & B6 & 70 & 0.5 \\
\hline A7 & 70 & 1.0 & B7 & 70 & 1.0 \\
\hline- & - & - & B8 & 70 & 1.5 \\
\hline- & - & - & B9 & 70 & 2.0 \\
\hline
\end{tabular}

$f_{c k}:$ Compressive strength of RC, $f_{c h f}:$ Compressive strength of SFR(H)C, $V_{f}$ : Volume fraction of fiber

Table 4 Test results of compressive strength.

\begin{tabular}{c|c|c|c|c|c}
\hline Name & $f_{c k f}(\mathrm{MPa})$ & $f_{c k f} / f_{c k}$ & Name & $f_{c k f}(\mathrm{MPa})$ & $f_{c k f} / f_{c k}$ \\
\hline \hline A1 & 49.1 & 1.00 & B1 & 62.7 & 1.00 \\
\hline A2 & 46.4 & 0.95 & B2 & 57.3 & 0.91 \\
\hline A3 & 55.1 & 1.12 & B3 & 66.3 & 1.06 \\
\hline A4 & 62.0 & 1.26 & B4 & 56.3 & 0.90 \\
\hline A5 & 73.5 & 1.00 & B5 & 62.2 & 1.00 \\
\hline A6 & 69.1 & 0.94 & B6 & 69.9 & 1.12 \\
\hline A7 & 84.4 & 1.15 & B7 & 79.0 & 1.27 \\
\hline- & - & - & B8 & 97.0 & 1.56 \\
\hline- & - & - & B9 & 105.8 & 1.70 \\
\hline
\end{tabular}

value of the three compressive strength $\left(f_{c k f}\right)$ of test cylinders.

As shown in Figure 1, there is no clear tendency of strength increase in the $50 \mathrm{MPa}$ specimen group according to increase of volume fraction of steel fibers $\left(V_{f}\right)$. This is the same result as that reported by Eren and Celik ${ }^{15}$. However, with the exception of the A6 specimen, the compressive strengths $\left(f_{c k f}\right)$ of the $70 \mathrm{MPa}$ group clearly increase as volume fraction of steel fibers $\left(V_{f}\right)$ increase, and this is the same observation reported from Narayanan and Darwish. ${ }^{13}$ Thus, the compressive strength of SFRC showed different tendency between the groups as the volume fraction of steel fibers $\left(V_{f}\right)$ changes. This result seems to imply that the compressive strength of SFRC are affected by the volume fraction of steel fibers $\left(V_{f}\right)$ at high-strength concrete while its effect becomes little as concrete strength decreases. There are, however, many different observations on the effect of volume fraction of steel fibers $\left(V_{f}\right)$ on the compressive strength of SFRC ${ }^{3,15,18}$, and thus, the results of this study are not sufficient to reach general conclusion on the compressive strength of SFRC.

\subsection{Test results of splitting tensile strength}

Table 5 and Figure 2 show the average values of the three splitting tensile strengths cast and tested for each of the mixtures.

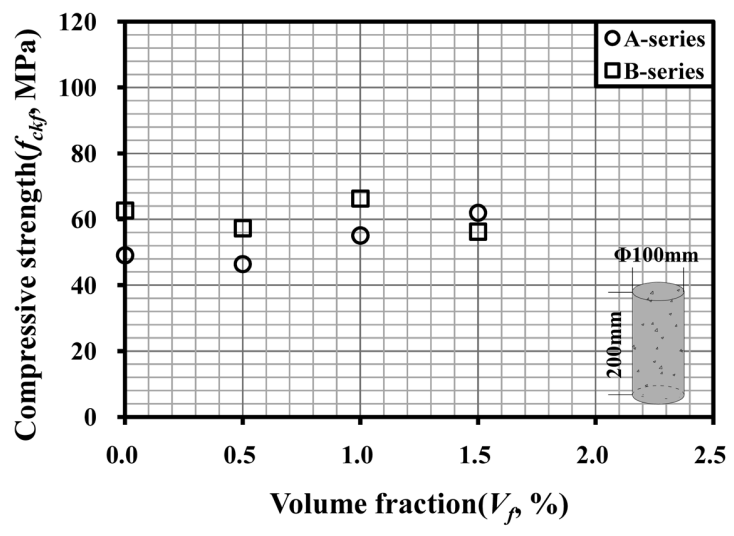

(a) Design compressive strength of $50 \mathrm{MPa}$

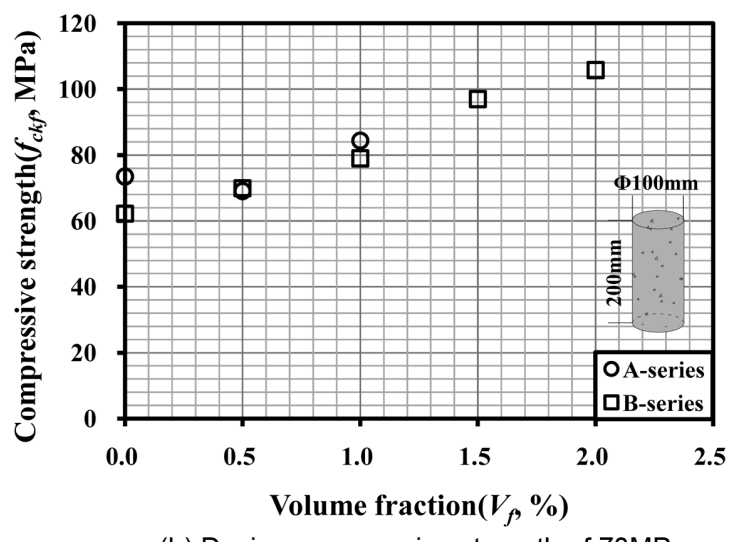

(b) Design compressive strength of $70 \mathrm{MPa}$

Fig. 1 Test results of compressive strength.

Table 5 Test results of splitting tensile strength.

\begin{tabular}{c|c|c|c|c|c}
\hline Name & $f_{\text {spf }}(\mathrm{MPa})$ & $f_{\text {spf }} / f_{\text {sp }}$ & Name & $f_{\text {spf }}(\mathrm{MPa})$ & $f_{\text {spf }} / f_{\text {sp }}$ \\
\hline \hline $\mathrm{A} 1$ & 4.12 & 1.00 & $\mathrm{~B} 1$ & 3.77 & 1.00 \\
\hline $\mathrm{A} 2$ & 4.23 & 1.03 & $\mathrm{~B} 2$ & 4.24 & 1.12 \\
\hline $\mathrm{A} 3$ & 4.41 & 1.07 & $\mathrm{~B} 3$ & 4.53 & 1.20 \\
\hline $\mathrm{A} 4$ & 5.13 & 1.25 & $\mathrm{~B} 4$ & 6.04 & 1.60 \\
\hline $\mathrm{A} 5$ & 4.28 & 1.00 & $\mathrm{~B} 5$ & 3.81 & 1.00 \\
\hline $\mathrm{A} 6$ & 4.68 & 1.09 & $\mathrm{~B} 6$ & 4.58 & 1.20 \\
\hline $\mathrm{A} 7$ & 5.92 & 1.38 & $\mathrm{~B} 7$ & 4.89 & 1.28 \\
\hline- & - & - & $\mathrm{B} 8$ & 6.26 & 1.64 \\
\hline- & - & - & $\mathrm{B} 9$ & 7.93 & 2.08 \\
\hline
\end{tabular}

The values of $f_{s p f} / f_{s p}$ in Table 5 are the splitting tensile strength of SFRC specimens $\left(f_{\text {spf }}\right)$ divided by splitting tensile strength of a specimen without any steel fiber $\left(f_{s p}\right)$ that are the control specimens. As shown in Table 5 and Figure 2, the splitting tensile strength of SFRC $\left(f_{s p f}\right)$ increased as the volume fraction of steel fibers $\left(V_{f}\right)$ increased. For the group A with a compressive strength of $50 \mathrm{MPa}$, the splitting tensile strength of SFRC $\left(f_{\text {spf }}\right)$ increased by $3 \%, 7 \%$, and $25 \%$ each, compared to the control specimens, when the volume fraction of steel fibers $\left(V_{f}\right)$ were $0.5 \%, 1.0 \%$, and $1.5 \%$, respectively. For the group A with a compressive strength of $70 \mathrm{MPa}$, the splitting tensile strength also significantly increased by $9 \%$ and $38 \%$ each, compared to the control specimens, when the volume fraction of steel fibers were $0.5 \%$ and $1.0 \%$, respectively. For the group B with a compressive strength of $50 \mathrm{MPa}$, the 


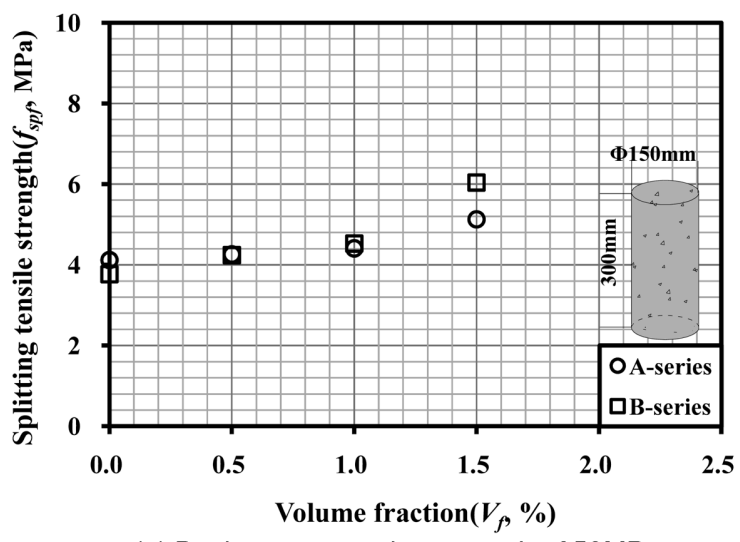

(a) Design compressive strength of $50 \mathrm{MPa}$

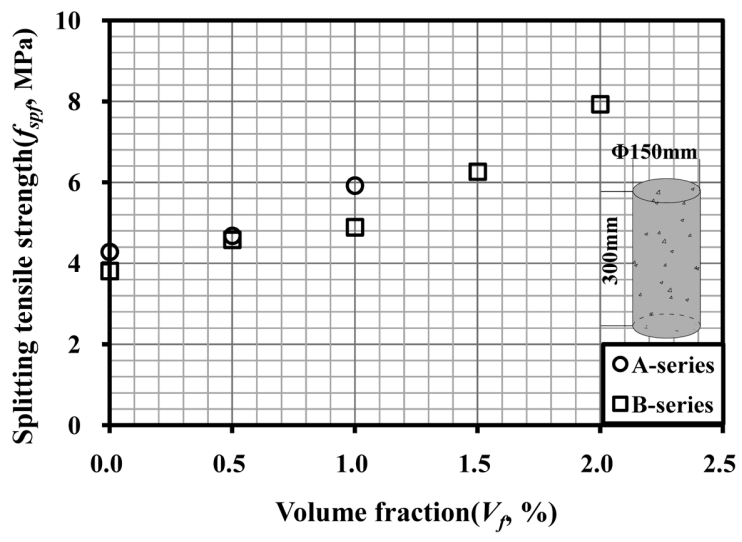

(b) Design compressive strength of $70 \mathrm{MPa}$

Fig. 2 Test results of splitting tensile strength.

splitting tensile strength $\left(f_{\text {spf }}\right)$ increased by $12 \%, 20 \%$, and $60 \%$ each, when the fiber mixing rates $\left(V_{f}\right)$ were $0.5 \%, 1.0 \%$, and $1.5 \%$, respectively. For the group B with a compressive strength of 70 $\mathrm{MPa}$, the splitting tensile strength $\left(f_{\text {spf }}\right)$ significantly increased by $20 \%, 28 \%, 64 \%$ and $104 \%$ each, when the volume fraction of steel fibers were $0.5 \%, 1.0 \%, 1.5 \%$ and $2.0 \%$, respectively. Different from the compressive strength of SFRC described in chapter 3.1, there was a clear increase in splitting tensile strength of SFRC $\left(f_{\text {spf }}\right)$ compared to normal concrete. This is because the fibers transfer the tensile stress between the cracks. The strengthening effects of steel fiber was found to be larger in high-strength concrete than normal strength concrete, which is considered to be due to the larger bonding stress of steel fibers in high-strength concrete. It should be noted that the fibers were pulled out at failure before reaching their tensile strength because of the very high tensile strength of fibers.

\subsection{Test results of modulus of rupture}

Table 6 and Figure 3 show the test results of the modulus of rupture. The values of $f_{r}$ used in Table 6 are each test results of the control specimens A1, A5, B1 and B5, which have no steel fibers. With the exception of specimen A4 and group A specimens with a compressive strength of $70 \mathrm{MPa}$, the modulus of rupture of SFRC $\left(f_{r f}\right)$ increased as the volume fraction of steel fibers $\left(V_{f}\right)$ increased. In the group A with compressive strength of $50 \mathrm{MPa}$, the modulus of rupture of SFRC specimens with $0.5 \%$ and $1.0 \%$ volume fraction of steel fibers $\left(V_{f}\right)$ increased by $15 \%$ and $45 \%$, compared to the specimens without fiber, respectively. For group B with a compressive strength of $50 \mathrm{MPa}$, the modulus of rupture of SFRC
Table 6 Test results of modulus of rupture.

\begin{tabular}{c|c|c|c|c|c}
\hline Name & $f_{r f}(\mathrm{MPa})$ & $f_{r f} / f_{r}$ & Name & $f_{r f}(\mathrm{MPa})$ & $f_{r f} / f_{r}$ \\
\hline \hline A1 & 4.51 & 1.00 & B1 & 4.07 & 1.00 \\
\hline A2 & 5.17 & 1.15 & B2 & 4.60 & 1.13 \\
\hline A3 & 6.53 & 1.45 & B3 & 7.00 & 1.72 \\
\hline A4 & 4.10 & 0.91 & B4 & 7.72 & 1.90 \\
\hline A5 & 6.10 & 1.00 & B5 & 3.51 & 1.00 \\
\hline A6 & 5.17 & 0.85 & B6 & 4.43 & 1.26 \\
\hline A7 & 5.70 & 0.93 & B7 & 6.46 & 1.84 \\
\hline- & - & - & B8 & 13.35 & 3.80 \\
\hline- & - & - & B9 & 7.33 & 2.09 \\
\hline
\end{tabular}

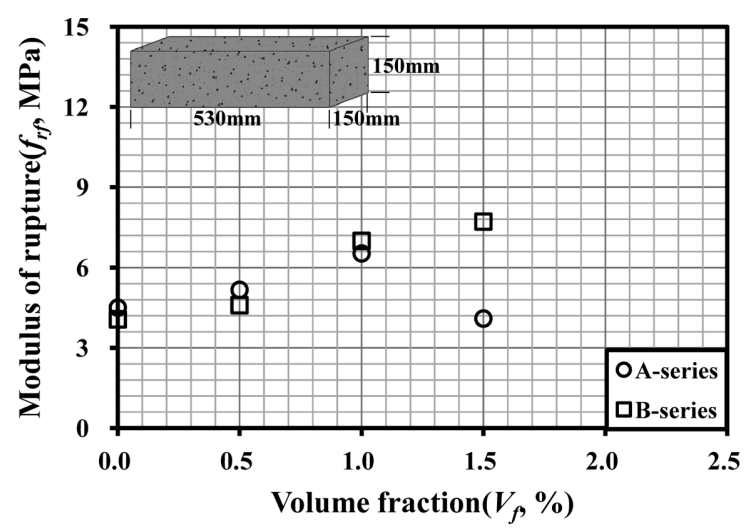

(a) Design compressive strength of $50 \mathrm{MPa}$

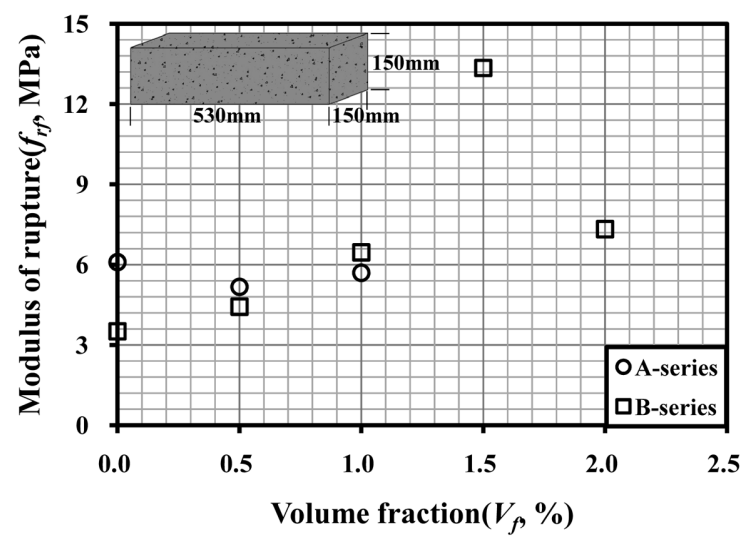

(b) Design compressive strength of $70 \mathrm{MPa}$

Fig. 3 Test results of modulus of rupture.

$\left(f_{r f}\right)$ increased by $13 \%, 72 \%$ and $90 \%$ each, compared to the conventional concrete specimens, when the volume fractions of steel fibers $\left(V_{f}\right)$ were $0.5 \%, 1.0 \%$ and $1.5 \%$. For the group B specimens with a compressive strength of $70 \mathrm{MPa}$, the modulus of rupture was increased by $26 \%, 84 \%, 280 \%$ and $109 \%$, when the volume fractions of steel fibers $\left(V_{f}\right)$ were $0.5 \%, 1.0 \%, 1.5 \%$ and $2.0 \%$, respectively.

\section{Proposed expressions on material strength}

As pointed out in the previous section, it was not clear whether the compressive strength of SFRC increases as the volume fraction of steel fibers $\left(V_{f}\right)$ increases, on which many researchers show different opinions. $12,14,17,19$ Therefore, further studies are required to clarify the strengthening effects of steel fiber on the 
compressive strength, and the scope of this study on compressive strength of SFRC is limited to presenting the experiment results. In this study, the strength equations on splitting tensile strength and modulus of rupture for SFRC were proposed, which were also compared to test results and calibrated to provide a proper margin of safety.

\subsection{Expression on splitting tensile strength}

The results of this study confirmed that the splitting tensile strengths $\left(f_{\text {spf }}\right)$ of SFRC increase as the volume fractions of steel fibers $\left(V_{f}\right)$ increase. However, since the number of specimens tested in this research was very limited, the experiment results were collected from previous studies, ${ }^{1,3,6,13-18,21,22}$ and a total of 134 test data was used for analysis. As shown in Table 7, the range of collected data included the volume fractions of steel fibers $\left(V_{f}\right)$ from 0.25 to $3.00 \%$, a fiber shape factor (aspect ratio, $L_{f} / D_{f}$ ) from 55 to 133 , and fiber types such as the hooked, crimped, and indented type.

Figure 4 shows the results of parametric analysis using the collected data. As shown in Figure 4(a) and (b), the tensile strength of SFRC increased as the volume fraction of steel fibers $\left(V_{f}\right)$ or fiber factor $\left(F_{1}\right)$ increased. Especially, the increasing rate of the tensile strength of SFRC can be more clearly seen against the fiber factor $\left(F_{1}\right)$,because it reflects both the volume fraction of steel fibers $\left(V_{f}\right)$ and the fiber shape factor $\left(\alpha_{f}\right)$. The fiber shape factor $\left(\alpha_{f}\right)$ indirectly reflect the bond strength of different types of steel fibers. Thus, considering the fiber factor $\left(F_{1}\right)$ as an important influential factor, the basic form of splitting tensile strength $\left(f_{s p f}\right)$ of SFRC was derived from a regression analysis as follows:

$$
f_{s p f}=\left(32.57 F_{1}+0.6853\right) \sqrt{f_{c k}}
$$

Figure 5 shows the ratio of test results to calculated splitting tensile strength $\left(f_{\text {spf }}\right)$ using eq. (7) $\left(f_{\text {spf }}(\right.$ test $) / f_{\text {spf }}($ Eq. 7$\left.)\right)$ according to the fiber factor $\left(F_{1}\right)$. The proposed splitting tensile strength of SFRC evaluated the test results accurately with a mean of 1.00 , a standard deviation of 0.21 and a COV of 0.21 . However, as shown

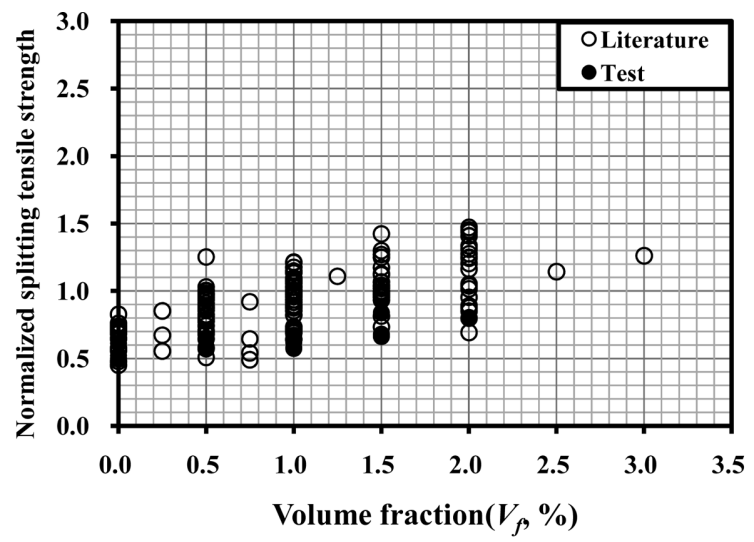

(a) Influence of fiber volume fraction

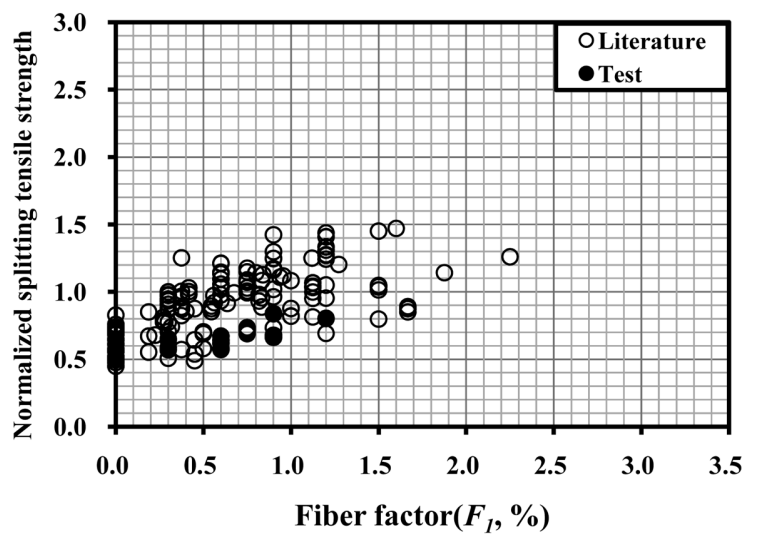

(b) Influence of fiber factor

Fig. 4 Parametric study on splitting tensile strength.

in Figure 5, splitting tensile strengths of SFRC $\left(f_{\text {spf }}\right)$ calculated by equation 7 provided the unconservative results on many specimens. Therefore, considering the characteristics of SFRC, such as balling of steel fibers, there is a need to consider the un-conservative results in order to secure not only accuracy but also sufficient margin of safety. Researchers can have different opinions on how much safety level to be secured, and various international codes actually adopt the different safety level. The fractile level $(F)$ for

Table 7 Database of splitting tensile strength and modulus of rupture test of SFR(H)C.

\begin{tabular}{|c|c|c|c|c|}
\hline Author & Number of specimen & $V_{f}(\%)$ & $L_{f} / D_{f}$ & Shape ${ }^{\dagger}$ \\
\hline Mansur et al. $^{22)}$ & $4(4)^{*}$ & $0.50 \sim 0.80$ & 60 & $\mathrm{H}$ \\
\hline Narayanan et al. $^{13)}$ & $19(0)^{*}$ & $0.30 \sim 3.00$ & $100 \sim 133$ & $\mathrm{C}$ \\
\hline Li et al. ${ }^{18)}$ & $2(2)^{*}$ & 1.00 & $60 \sim 100$ & $\mathrm{H}$ \\
\hline Wafa and Ashour $^{14)}$ Ashour et al. ${ }^{21)}$ & $24(24) *$ & $0.25 \sim 1.50$ & 75 & $\mathrm{H}$ \\
\hline Eren and Celik $^{15)}$ & $27(0)^{*}$ & $0.50 \sim 2.00$ & $60 \sim 83$ & $\mathrm{H}$ \\
\hline Song et al. ${ }^{16)}$ & $4(4)^{*}$ & $0.50 \sim 2.0$ & 64 & $\mathrm{H}$ \\
\hline Yun and Park ${ }^{6}$ & $17(17)^{*}$ & $0.50 \sim 2.00$ & $56-80$ & $\mathrm{H}, \mathrm{C}, \mathrm{I}$ \\
\hline Thomas and Ramaswamy ${ }^{17)}$ & $9(9)^{*}$ & $0.50 \sim 1.50$ & 55 & $\mathrm{H}$ \\
\hline Kim et al. ${ }^{3)}$ & $24(12)^{*}$ & $0.50 \sim 2.00$ & 60 & $\mathrm{H}$ \\
\hline $\mathrm{Oh}^{5)}$ & $0(12)^{*}$ & $1.00 \sim 3.00$ & $62 \sim 73$ & $\mathrm{H}$ \\
\hline Karl et al. ${ }^{1)}$ & $4(4)^{*}$ & $0.50 \sim 2.00$ & 60 & $\mathrm{H}$ \\
\hline Total & $134(88)^{*}$ & $0.25 \sim 3.00$ & $55 \sim 133$ & $\mathrm{H}, \mathrm{C}, \mathrm{I}$ \\
\hline
\end{tabular}

*() : No. of modulus of rupture test specimens

${ }^{\dagger} \mathrm{H}$ : Hooked type, C: Crimped type, I: Indented type

Note : No. of specimen was counted excluding the conventional concrete specimens. 


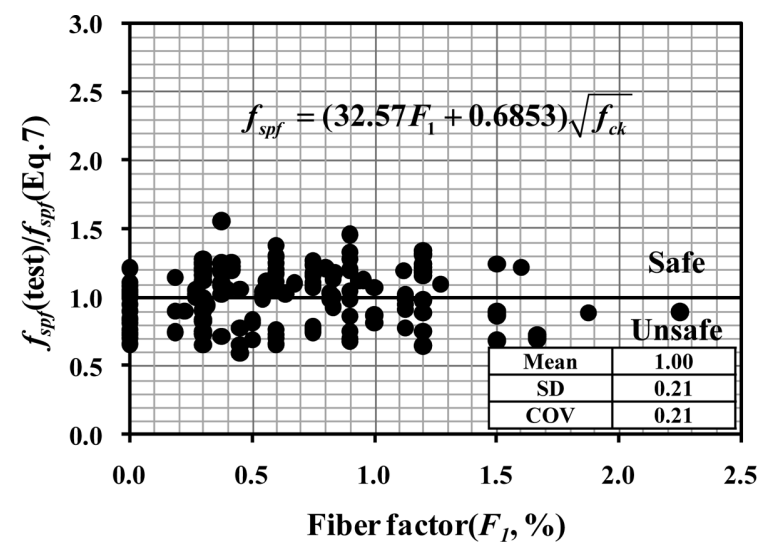

Fig. 5 Evaluation of Eq.7.

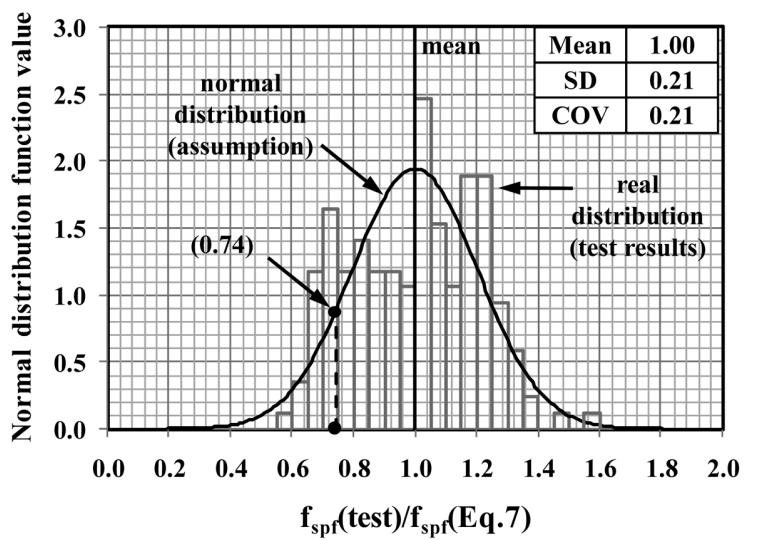

Fig. 6 Fractile level based on Eq. (7). (normal distribution of data assumed)

the compressive strength of conventional concrete, which is tested using cylinder specimens, specified in U.S. code ${ }^{23}$ is $9 \%$, and Kim et al. ${ }^{11}$ evaluated the shear strength equations of reinforced concrete based on the fractile value of $10 \%$. Thus, a similar fractile level $(F)$ of $10 \%$ was considered for this study. Then, with an assumption that the ratios of the splitting tensile strength obtained from test results to the calculated values by equation $7\left(f_{\text {spf }}(\right.$ test $) /$ $f_{\text {sp } f}($ Eq. 7)) approaches a normal distribution, the value of the $x$ axis where the fractile level is $0.1(10 \%)$ is about 0.74 . Thus, if the average value of $\left(f_{s p f}(\right.$ test $) /$ spf $($ Eq. 7$\left.)\right)$ is moved as shown in Figure 7 and 0.74 is multiplied to equation (7) so that the fractile level $(F)$ is 1.00 when the $x$ axis value is 1.00 , the splitting tensile strength $\left(f_{\text {spf }}\right)$ of SFRC is simply expressed as follows:

$$
f_{s p f}=\left(24 F_{1}+0.5\right) \sqrt{f_{c k}}
$$

In other words, there is less than $10 \%$ probability of the splitting tensile strength $\left(f_{s p f}\right)$ of SFRC being under the value calculated in equation (8). Also, when no fibers are included in mixture, the fiber factor $\left(F_{1}\right)$ in equation (8) becomes 0 , and it results in the splitting tensile strength of conventional concrete presented by the ACI code ${ }^{23}$, that is $f_{s p}=0.5 \sqrt{f_{c k}}$. Therefore, equation (8) not only reflects an appropriate safety margin based on reliability analysis, but can also be applied to the estimation of splitting tensile strength of both conventional concrete and steel fiberreinforced concrete.

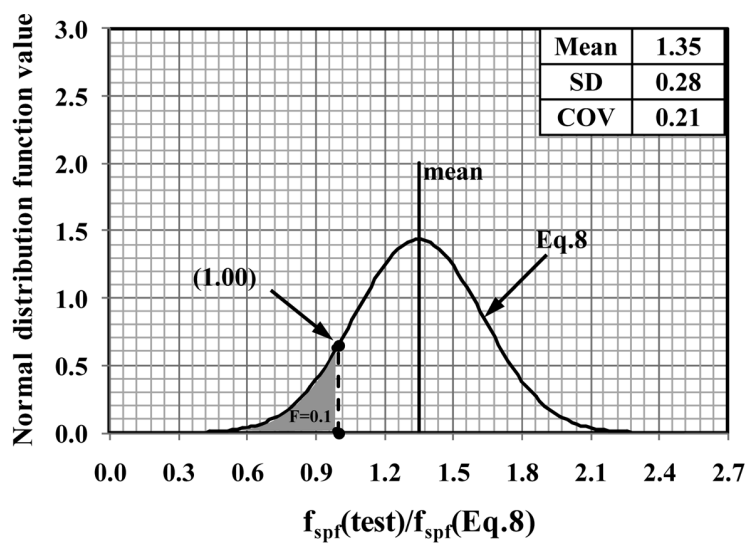

Fig. 7 Fractile level based on the calibrated mean value from Eq. (8). (normal distribution of data assumed)

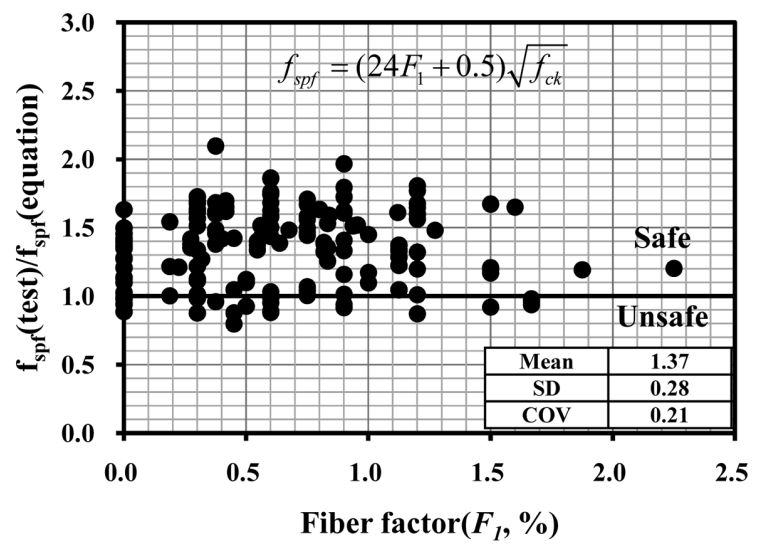

Fig. 8 Evaluation of proposed splitting tensile strength equation (Eq. (8)) for SFR(H)C.

Figure 8 and Figure 9 show the evaluation results of the splitting tensile strength of SFRC by proposed equation (8) in this study and equations proposed by other researchers, repectively. The results of equation (8) showed a mean of 1.37 , SD of 0.28 , and $\mathrm{COV}$ of 0.21 , which is the lowest COV value among the evaluation equations studied in this study, and thus it provided better safety margin and accuracy than the other equations. Equation (1) presented by Narayanan and Darwish ${ }^{13}$ was found to reflect the effects of the fiber factor $\left(F_{1}\right)$ comparatively well, and generally showed safe results. However, the equation proposed in this study only has un-conservative results for under $10 \%$, whereas the equation proposed by Narayanan and Darwish ${ }^{13}$ has the fractile level of $0.21(21 \%)$ giving larger numbers of un-conservative estimations of the splitting tensile strength $\left(f_{\text {spf }}\right)$. Equation (2-2) presented by Wafa and Ashour ${ }^{14}$ provided very conservative results, because the effect of fiber factor $\left(F_{1}\right)$, which is an important influencing factor to splitting tensile strength $\left(f_{\text {spf }}\right)$ of SFRC, was not included. Consequently, it tended to be more conservative as the fiber factor $\left(F_{1}\right)$ got higher. The evaluation results of equation (4-2) proposed by Song and Hwang ${ }^{16}$ were also very similar to that proposed by Wafa and Ashour ${ }^{14}$. The equation (5-2) proposed by Thomas and Ramaswamy ${ }^{17}$ had the lowest value of standard deviation out of the many different equations, and it considered the effects of the fiber factor $\left(F_{1}\right)$ reasonably well. On the other hand, however, it provided the largest number of unsafe data among all other equations considered 


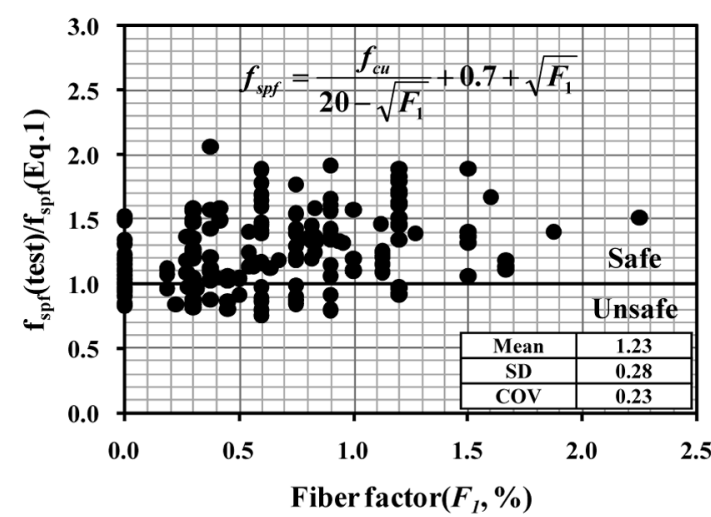

(a) Narayanan and darwish ${ }^{13}$

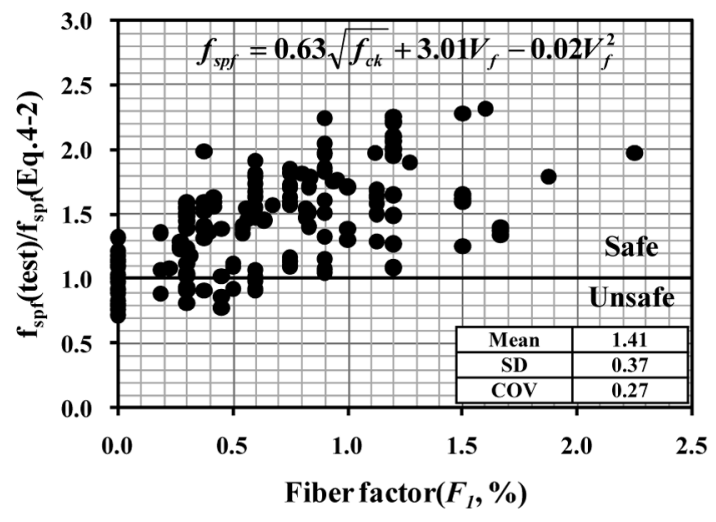

(c) Song and Hwang ${ }^{16)}$

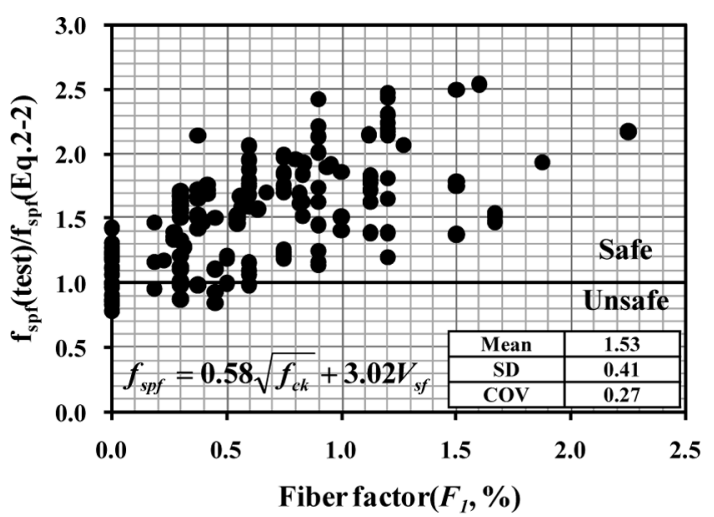

(b) Wafa and Ashour ${ }^{14}$

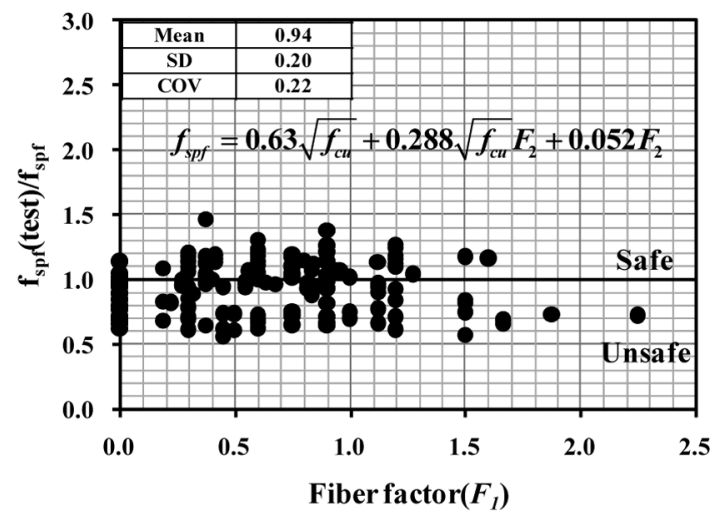

(d) Thomas and Ramaswamy ${ }^{17)}$

Fig. 9 Evaluation of splitting tensile strength equations for SFR(H)C by other researchers.

in this research, which implies that the consideration of safety appeared to be an issue.

\subsection{Expression on modulus of rupture}

Test results of eighty eight SFRC modulus of rupture were collected from previous studies as shown in Table 7. 1,3,5,6,14,16$18,21,22$ The range of collected data included the volume fraction of steel fibers $\left(V_{f}\right)$ from $0.25 \%$ to $3.00 \%$, a fiber aspect ratio $\left(L_{f} / D_{f}\right)$ from 55 to 100 , and different types of fiber, such as hooked, crimped, and indented types.

Figure 10 (a) and (b) show the influence of the volume fraction of steel fibers $\left(V_{f}\right)$ and the fiber factor $\left(F_{1}\right)$ on the modulus of rupture of SFRC $\left(f_{r}\right)$, using the collected data shown in Table 7. It shows that the modulus of rupture of SFRC $\left(f_{r}\right)$ increases as the volume fraction of steel fibers $\left(V_{f}\right)$ or fiber factor $\left(F_{1}\right)$ increase, and especially, the increase trend is more clearly seen for fiber factor $\left(F_{1}\right)$. Thus, based on the observation, this study considered the fiber factor $\left(F_{1}\right)$ as the primary influencing parameter, and modulus of rupture $\left(f_{r f}\right)$ of SFRC was derived as follows:

$$
f_{r f}=\left(57.03 F_{1}+0.8434\right) \sqrt{f_{c k}}
$$

Figure 11 shows the ratio of test results to the calculated modulus of rupture by equation $9\left(f_{r f}(\right.$ test $\left.) / f_{r f}(E q .9)\right)$ against the fiber factor $\left(F_{1}\right)$. The values of $f_{r f}($ test $) / f_{r f}(E q .9)$ show a mean of 1.00 , SD of 0.26 , and COV of 0.27 , which are considered to imply that equation (9) reasonably well estimates the modulus of rupture of SFRC $\left(f_{r f}\right)$. However, just as the case with the splitting tensile

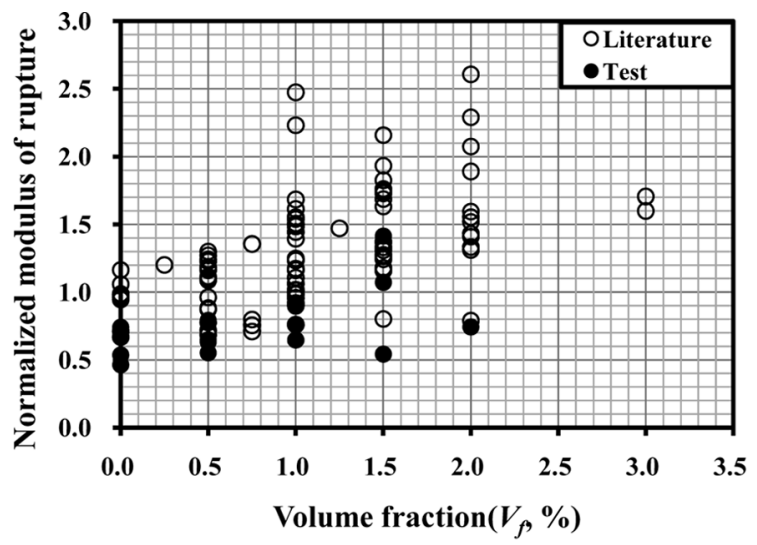

(a) Influence of fiber volume fraction

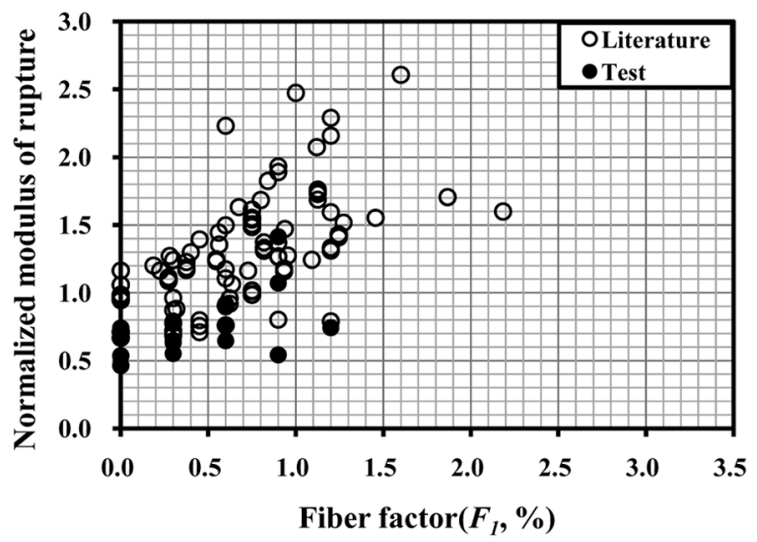

(b) Influence of fiber factor

Fig. 10 Parametric study on modulus of rupture of SFRC. 


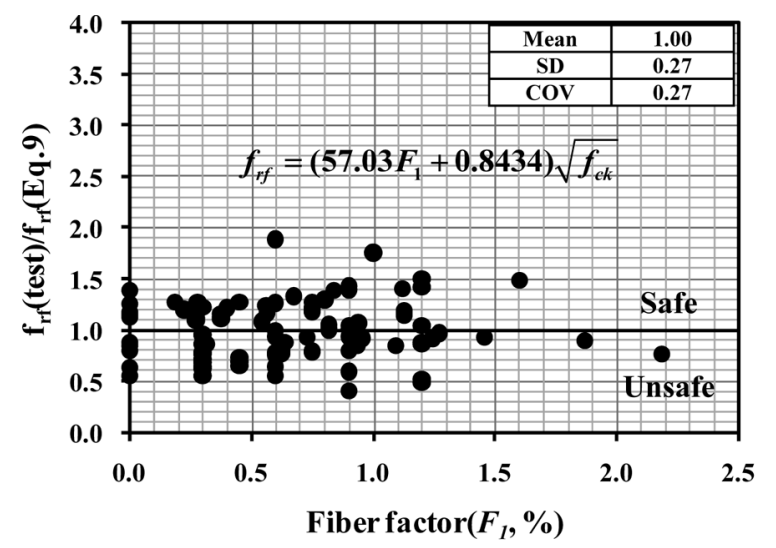

Fig. 11 Evaluation of Eq. (9).

strength evaluation equation, there were many cases that the results of the modulus of rupture calculated from equation (9) were un-conservative compared to the actual experimental values. Therefore, assuming that ratio of $f_{r}($ test $) / f_{r f}(E q .9)$ approaches a normal distribution, $f_{r f}($ test $) / f_{r f}(E q .9)$ is around 0.65 when the fractile level ${ }^{11}$ is 0.1 as shown in Figure 12. Thus, as shown in Figure 13, equation (9) can be modified in simple form to provide the unsafe estimation less than $10 \%$, that is:

$$
f_{r f}=\left(37 F_{1}+0.55\right) \sqrt{f_{c k}}
$$

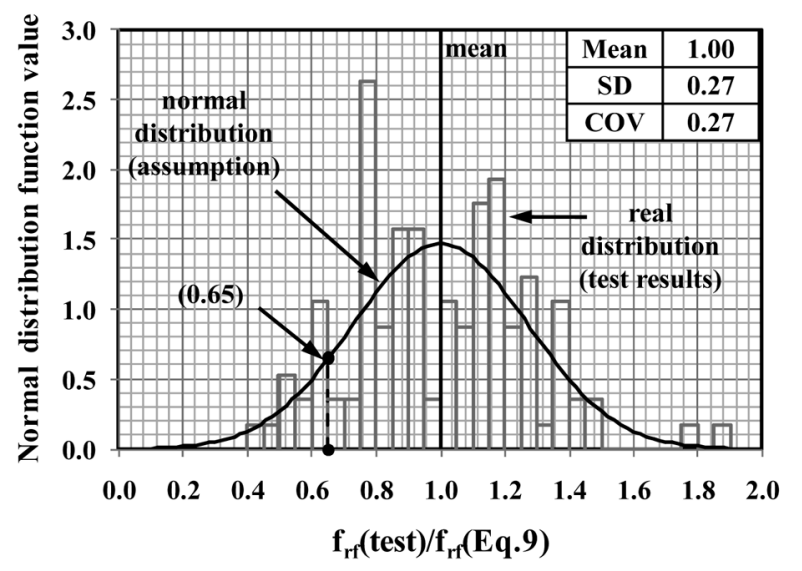

Fig. 12 Fractile level based on Eq. (9). (normal distribution of data assumed)

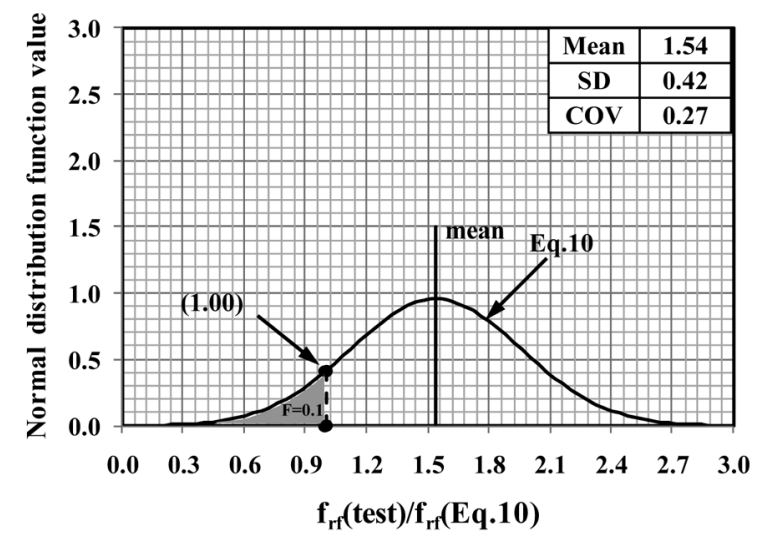

Fig. 13 Fractile level based on the calibrated mean value from Eq. (10). (normal distribution of data assumed)

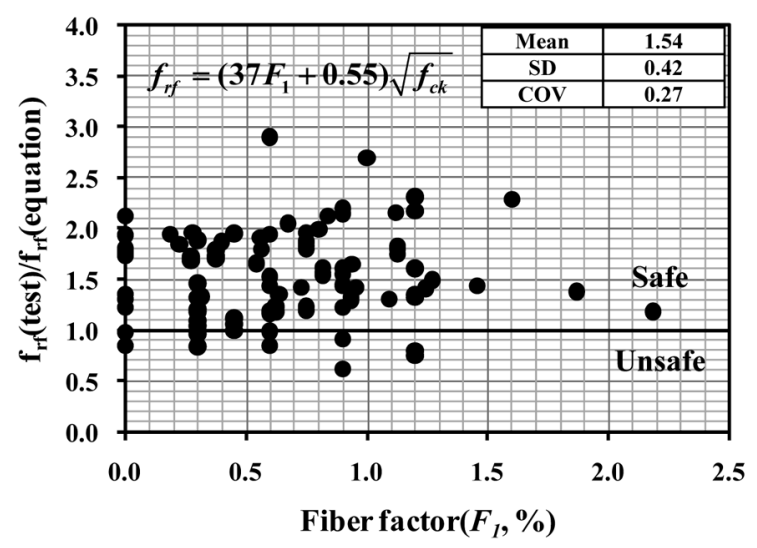

Fig.14 Evaluation of proposed modulus of rupture equation (Eq. (10)) for SFR(H)C.

The equation (10) is considered to have sufficiently reflected the uncertainty of the material strength, and also be applied to estimate the modulus of rupture for both conventional concrete and steel fiber-reinforced concrete. For conventional concrete without steel fibers, equation (10) gives $f_{r}=0.55 \sqrt{f_{c k}}$, which is slightly different from that of conventional concrete specified in the ACI code. ${ }^{23}$

Figure 14 and Figure 15 present the evaluation results of equation 10 proposed in this study and the equations from other studies ${ }^{5,14,16,17}$ compared to the experiment results. The equation (10) provided the mean 1.54, the SD 0.42, and the COV 0.27, which is the most accurate estimation of the modulus of rupture of SFRC $\left(f_{r f}\right)$ among the equations presented in this study. Also, as mentioned above, it should be noted that sufficient safety is secured based on the reliability analysis. Equation (2-3) by Wafa and Ashour ${ }^{14}$ and equation (4-3) by Song and Hwang ${ }^{16}$ did not consider the effects of the fiber factor $\left(F_{1}\right)$ properly. As a result, the modulus of rupture of SFRC $\left(f_{r}\right)$ is largely underestimated as the fiber factor $\left(F_{1}\right)$ becomes larger, and a large portion of estimated results by equation (2-3) are also un-conservative. Equation (5-3) by Thomas and Ramaswamy ${ }^{17}$ overestimated the modulus of rupture $\left(f_{r f}\right)$ of SFRC specimens providing no margin of safety for a large number of specimens. The equation (6) proposed by $\mathrm{Oh}^{5}$ well considered the effects of the fiber factor $\left(F_{1}\right)$ on the modulus of rupture of $\operatorname{SFRC}\left(f_{r f}\right)$, but there were many cases of un-conservative estimation. Therefore, it is shown that the modulus of rupture of SFRC proposed in this study is more proper than the existing equations in terms of safety as well as accuracy.

\section{Conclusions}

In this study, experimental tests have been conducted on the material characteristics of SFRC with the primary variables of concrete compressive strength $\left(f_{c k}\right)$ and volume fraction of steel fibers $\left(V_{f}\right)$. An extensive literature review has also been performed, from which a database of material test results on SFRC has been established. Based on parametric and reliability analysis, improved equations for the material strengths of SFRC have been proposed. The following conclusions were obtained from this study.

1) The splitting tensile strength of SFRC $\left(f_{s p f}\right)$ increased as the volume fraction of steel fibers $\left(V_{f}\right)$ increased, whose increment was observed to be up to approximately twice as much as conventional concrete. 


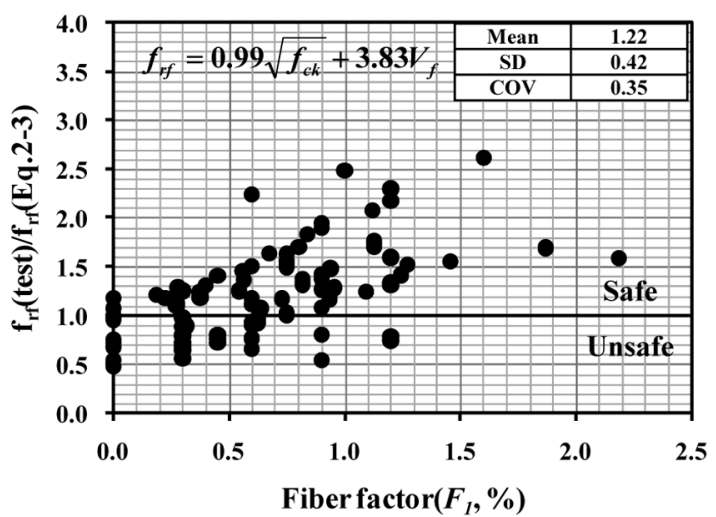

(a) Wafa and Ashour ${ }^{14}$

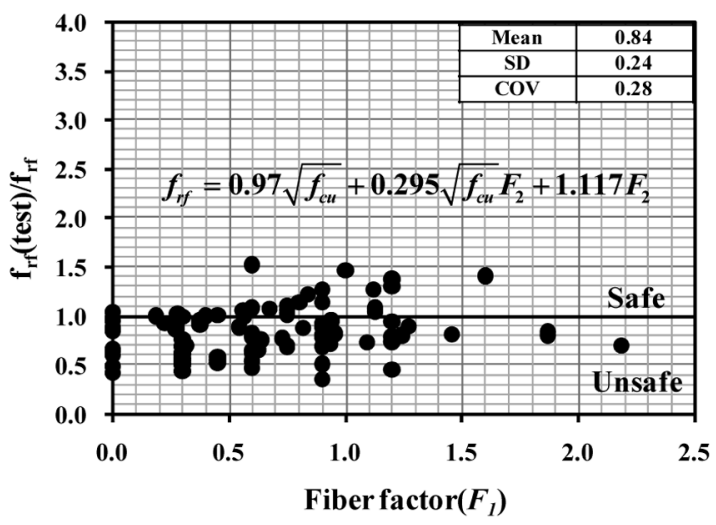

(c) Thomas and Ramaswamy ${ }^{17)}$

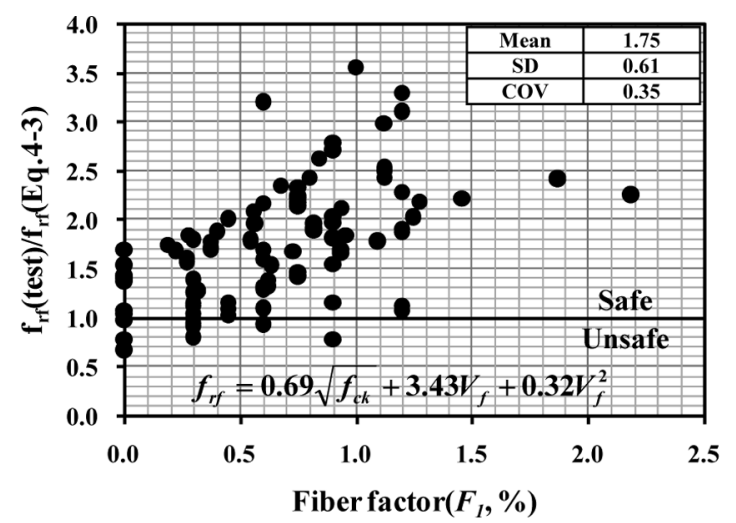

(b) Song and Hwang ${ }^{16)}$

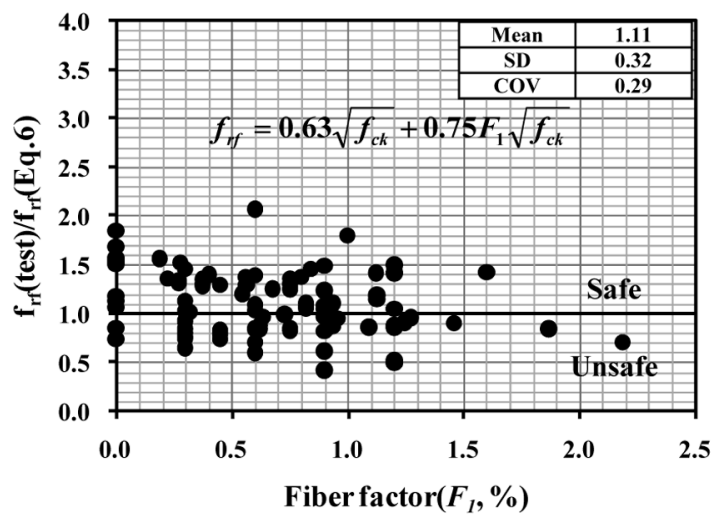

(d) $\mathrm{Oh}^{5)}$

Fig. 15 Evaluation of modulus of rupture equations for $S F R(H) C$ by other researchers.

2) The modulus of rupture of SFRC $\left(f_{r f}\right)$ significantly increased as the volume fraction of steel fibers $\left(V_{f}\right)$ increased, and it was significantly enhanced up to about four times compared to conventional concrete.

3) The equations for evaluation of splitting tensile strength and modulus of rupture of SFRC proposed in this study are not only accurate, but also appear to be rational in terms of reliability or safety.

4) Compared to conventional concrete, the compressive strength of SFRC increased at high-strength as the volume fraction of steel fibers $\left(V_{f}\right)$ increased, whereas no increase of compressive strength was observed at normal strength in this study. However, as different researchers have different opinions about the effect of steel fibers on the compressive strength, further studies are required on this issue.

\section{Acknowledgments}

This work was supported by the Korea Research Foundation Grant funded by the Korean Government (MOEHRD, General Research Promotion Fund) (KRF-2009-0070821).

\section{References}

1. Karl, K. W., Kim, K. S., Lee, D. H., Hwang, J. H., and Oh, Y. H., "Experimental Study on Shear Strength of Steel Fiber Reinforced Concrete Beams," Journal of the Korea Institute for Structural Maintenance Inspection, Vol. 14, No. 3, 2010, pp. 160 170.

2. ACI Committee 544, "Design Considerations for Steel
Fiber Reinforced Concrete (ACI 544.4R-88)," ACI structural Journal, Vol. 85, No. 5, 1988, pp. 563 580.

3. Kim, Y. I., Lee, Y. K., and Kim, M. S., "Influence of Steel Fiber Volume Ratios on Workability and Strength Characteristics of Steel Fiber Reinforced High-Strength Concrete," Journal of the Korea Institute of Building Construction, Vol. 8, No. 3, 2008, pp. 75 83.

4. Swamy, R. N. and Mangat, P. S., "Influence of Fiber Geometry on the Properties of Steel Fiber Reinforced Concrete," Cement and Concrete Research, Vol. 4, No. 3, 1974, pp. 451 465.

5. Oh, Y. H., "Evaluation of Flexural Strength for Normal and High Strength Concrete with Hooked Steel Fibers," Journal of the Korea Concrete Institute, Vol. 20, No. 4, 2008, pp. 531 539.

6. Yoon, E. S. and Park, S. B., "An Experimental Study on the Mechanical Properties and Long-Term Deformations of HighStrength Steel Fiber Reinforced Concrete," Journal of Civil Engineering, KSCE, Vol. 26, No. 2A, 2006, pp. 401 409.

7. Batson, G. "Steel Fiber Reinforced Concrete," Materials Science and Engineering, Vol. 25, 1976, pp. 53 58.

8. Demeke, A. and Tegos, I. A., "Steel Fiber Reinforced Concrete in Biaxial Stress Tension-Compression conditions," ACI Structural Journal, Vol. 91, No. 5, 1994, pp. 579 584.

9. Shah, S.P., Weiss, J., and Yang, W., 1998. "Shrinkage Cracking - Can It Be Prevented?", Concrete International, Vol. 20, No. 4, April 1998, pp. 51 55.

10. Oslejs, J., "New Frontiers for Steel Fiber-Reinforced Concrete," Concrete international, Vol. 30, No. 5, 2008, pp. 45 50.

11. Kim, K. S. and Kim, S. S., "Evaluation of Shear Design Provisions for Reinforced Concrete Beams and Prestressed Con- 
crete Beams," Journal of the Korea Concrete Institute, Vol. 17, No. 5, 2005, pp. 717 726.

12. Szerszen, M. M. and Nowak, A. S., "Calibration of Design Code for Buildings (ACI 318): Part 2. Reliability Analysis and Resistance Factors," ACI Structural Journal, Vol. 100, No. 3, pp. 383 391.

13. Narayanan, R. and Darwish, I. Y. S., "Use of Steel Fibers as Shear Reinforcement," ACI Structural Journal, Vol. 84, No. 3, 1987, pp. 216 227.

14. Wafa, F. F., and Ashour, S. A., "Mechanical properties of High-Strength Fiber Reinforced Concrete," ACI Materials Journal, Vol. 89, No. 5, 1992, pp. 449 455.

15. Eren, O. and Celik, T., "Effect of Silica Fume and Steel Fibers on Some Properties of High-Strength Concrete," Construction and Building Materials, Vol. 11, No. 7-8, 1997, pp. 373 382.

16. Song, P. S. and Hwang, S., "Mechanical Properties of High-Strength Steel Fiber-Reinforced Concrete," Construction and Building Materials, Vol. 18, No. 9, 2004, pp. 669 673.

17. Thomas, J. and Ramaswamy, A., "Mechanical Properties of Steel Fiber-Reinforced Concrete," Journal of Materials in Civil Engineering, ASCE, Vol. 19, No. 5, 2007, pp. 385 392.
18. Li, V. C., Ward, R., and Hamza, A. M., "Steel and Synthetic Fibers as Shear Reinforcement," ACI Materials Journal, Vol. 89, No. 5, 1992, pp. 499 508.

19. Choi, K. K., Park, H. G, and Wight, J. K., "Shear Strength of Steel Fiber-Reinforced Concrete Beams without Web Reinforcement," ACI Structural Journal, Vol. 104, No. 1, pp. 12 21.

20. Khuntia, M, Stojadinovic, B. and Goel, S. C., "Shear Strength of Normal and High-Strength Fiber Reinforced Concrete Beams without Stirrups," ACI Structural Journal, Vol. 96, No. 2, pp. 282 290.

21. Ashour, S. A., Hasanain, G. S., and Wafa, F. F., "Shear Behavior of High-Strength Fiber Reinforced Concrete Beams," ACI Structural Journal, Vol. 89, No. 2, 1992, pp. 176 184.

22. Mansur, M. A., Ong, K. C. G., and Paramasivam, P., "Shear Strength of Fibrous Concrete Beams without Stirrups," Journal of Structural Engineering, ASCE, Vol. 112, No. 9, 1986, pp. 2066 2079.

23. ACI Committee 318, "Building Code Requirements for Structural Concrete (ACI 318M-08) and Commentary," American Concrete Institute, Farmington Hills, 2008, 473 pp. 